\title{
"ESTUDANTES DEMOCRÁTICOS": A ATUAÇÃO DO MOVIMENTO ESTUDANTIL DE "DIREITA" NOS ANOS 1960
}

\author{
Katya Zuquim Braghini* \\ Andrezza Silva Cameski
}

\begin{abstract}
RESUMO: A intenção deste artigo é apresentar os atos de uma juventude estudantil de "direita", com um exame intermediado pelas açóes feitas pelos seus pares etários de "esquerda", nos anos 1960, no Brasil. Esse estudo foi possível por meio da análise do conteúdo de uma revista educacional mensal, conservadora, publicada pela Editora do Brasil S/A, editora que alçou o posto de principal produtora de livros didáticos do país, em 1972. Para depreciar uma juventude estudantil que atuava politicamente nas ruas, este periódico fez emergir a atuação de outro grupo estudantil, considerado por eles "saudável" e "bom" que, ao seu modo, também agiu politicamente, fosse atuando com práticas diversificadas, fosse ficando em silêncio.
\end{abstract}

Palavras-chave: Movimento estudantil. Juventude. Pensamento Conservador.

\section{"DEMOCRATIC STUDENTS": THE ACTIONS OF THE "RIGHT-WING" STUDENT MOVEMENT IN THE 1960S}

ABSTRACT: This article aims to show the actions of right-wing young students, in the 1960s, in Brazil, through the analysis of the actions taken by their "left-wing" colleagues with the same age as them. This work was possible through the analysis of the content of a conservative monthly issue educational magazine, published by Editora do Brasil $S / A$, a publishing house that acquired the position of the main textbook publisher in the country, in 1972. To belittle the young students who acted politically on the streets, this magazine made another student group arise, which was considered by them as "healthy" and "good" who, in their own way, also acted politically, either through diversified practices, or silently.

Keywords: Student movement. Youth. Conservative thinking.

\footnotetext{
* Pontifícia Universidade Católica de São Paulo, Programa de Estudos Pós-graduados em Educação:
} História, Política, Sociedade. São Paulo, SP., Brasil. E-mail de contato: kmbrashini@pucsp.br. 


\section{“DES ÉTUDIANTS DÉMOCRATIQUES": L'ACTION DU MOUVEMENT ÉTUDIANT DE “DROITE” DES ANNÉES SOIXANTE}

RÉSUMÉ: Le but de cet article est de présenter les actes d'une jeunesse étudiante de "droite", avec un examen véhiculé par les actions faites au Brésil par ses binômes de "gauche" et même tranche d'âge, pendant les années soixante. Cette étude a été conçue grâce à l'analyse de contenu d'une revue éducationnelle mensuelle, conservatrice, publiée par la maison d'édition Editora do Brasil S/A, qui est devenue la principale productrice d'ouvrages didactiques du pays, en 1972. Pour nuire à une jeunesse étudiante qui agissait politiquement dans les rues, ce journal a fait émerger le comportement d'un autre groupe étudiant, considéré par eux comme "sain" et "bon" et qui, à leur façon, a aussi agi politiquement, soit avec des pratiques diversifiées, soit en restant silencieux.

Mots-clés: Mouvement étudiant. Jeunesse. Pensée conservatrice.

\section{Introdução}

$\mathrm{P}$

rivilegiamos no artigo a história de um movimento estudantil que aprovava a condução política do governo militar, após o golpe de estado em 1964, e fez oposição à ação de seus colegas, pares etários, considerados "comunistas". Esse agrupamento estudantil se apresentou como um grupo social atuante no trabalho de materialização do regime instituído, demonstrando um dinamismo diferenciado das grandes manifestações de rua, mas que nem por isso, deixou de revelar a sua posição política.

$\mathrm{Na}$ imprensa de circulação em massa, eram apresentados como estudantes modelares aqueles grupos que não praticavam política estudantil explícita; manifestavam-se favoráveis ao movimento golpista; faziam bloqueio às açóes de seus oponentes, ora por meio de atuaçóes convencionalmente aceitas, ora de formas violentas de ação. Tratamos aqui de estudantes que eram considerados modelos "exemplares" de jovens, de modo a apresentar outros desenhos estudantis e juvenis, expondo um tipo de manifestação pouco examinada pela historiografia.

Fosse para fazer empecilho e contraponto aos movimentos estudantis contrários à ditadura, fosse atuando de formas "modelares", por meio de comportamentos considerados "aceitáveis", pudemos perceber que, oculto e apagado, esse movimento também teve um passado para ser historicizado. No artigo, eles são chamados de movimento estudantil de "direita" por conta das suas açóes, apontadas como convenientes para o fechamento político do regime e para a manutenção da Ditadura Militar. 
O estímulo para a confecção deste artigo aconteceu após as perspectivas de pesquisa apresentadas por Hilsdorf e Peres (2009), Sanfelice (2008) e Sarlo (2007).

Hilsdorf e Peres (2009) analisaram os estudos históricos sobre a juventude entre 1999-2006. Segundo esse levantamento, há uma concentração de estudos sobre a década de 1960-1970, dando ênfase aos aspetos ligados ao movimento estudantil. $\mathrm{O}$ foco dos trabalhos está centralizado na atuação política dos estudantes contra o autoritarismo militar, desconsiderando tanto o aspecto "estudantil" do movimento, quanto a existência de grupos juvenis que se posicionassem a favor do governo militar. Além disso, as pesquisadoras apontam para um bloco de análises que formaliza uma imagem monolítica dos estudantes, como se todos eles fossem rebeldes e militantes, desconsiderando a existência de um contingente juvenil que não se manifestava nas ruas ou, simplesmente, se comportava de outras maneiras.

Sanfelice (2008) nos adverte sobre a escrita da história que tem em vista somente o recorte da União Nacional dos Estudantes (UNE). De acordo com o autor isso é como "contar uma parte da história", ainda que seja uma parte importante dela. O autor deixa claro que nem todos os estudantes universitários dos anos 1960 participaram do movimento estudantil e que nem todos reconheciam a UNE como sua representante.

Sarlo (2007) apontou uma preocupação em torno das fontes documentais como elemento fundamental para a identificação de traços significativos na história da ditadura militar, no caso, argentina, a partir da necessidade de criação de um sistema de hipóteses em que fossem captadas as contradições sociais. Para isso, pedia por pesquisas que buscassem pela variação documental. Essa ideia deu ênfase à curiosidade em torno dos registros de grupos partidários ao governo militar e avessos às grandes mobilizaçóes juvenis. Por isso, deu-se privilégio ao conteúdo da Revista de Editora do Brasil S/A (EBSA), periódico educacional mensal, porque ele claramente se apresentava como parceiro do governo instituído com o golpe de 1964 .

Ao longo da década de 1960, os editores desse periódico passaram a valorizar os artigos publicados em jornais diários, transformando a revista em um clipping mensal das notícias que, segundo eles, eram destaque ao longo do mês. Deste modo, foram vários os órgãos de imprensa citados pela revista, em sua seção Opinióes do mês, dentre eles, os jornais: O Estado de S. Paulo (Oesp), a Folha de S. Paulo (FSP), O Globo (Rio de Janeiro), e o Diário de Notícias (Rio de Janeiro). ${ }^{1}$ A ideia era dotar os profissionais da área educacional com diversas informações geradas em diferentes instâncias políticas. Deste modo, os seus editores compilavam artigos de outros órgãos de informação, leis, atas de comissóes de ensino etc. $\mathrm{O}$ artigo faz um mapeamento das discussóes apresentadas nas páginas desse periódico educacional e por aqueles que eram apresentados em suas páginas 
como referências confiáveis de modo a elencar as representaçóes advindas da inter-relação de grupos oponentes.

Os discursos sobre a juventude eram conteúdos ideologizados, que repetiam de forma incessante a ideia de que alguns jovens estudantes brasileiros eram "subversivos" e "comunistas" e que, em contrapartida, outros tantos jovens eram "bons estudantes" e dignos de exemplo. Os documentos partiam da ideia de que a subversão era um malefício que qualificava os jovens observados e criticados. Essa palavra foi tornada lugar-comum, usada como forma de apagamento de outros atributos desses estudantes.

$\mathrm{O}$ artigo foi organizado a partir de duas perspectivas metodológicas. A primeira tem em vista o estudo do estereótipo. Martins (2008) afirma que o senso comum e estereótipos não são apenas "[...] instrumentos das repetiçóes e dos processos que mobilizam a vida de cada um e de todos [...]”. (MARTINS, 2008, p. 52) Para o autor, o senso comum é comum não simplesmente porque se torna banal, mas porque é um conhecimento compartilhado entre sujeitos na relação social. Torna-se interessante pensar, tanto nos significados produzidos e compartilhados no momento de sua confecção, quanto no método de produção desses significados, já que o senso comum depende da interação social. (MARTINS, 2008, p. 54-55)

A segunda perspectiva pensa que no discurso foi estabelecido o confronto entre duas culturas. Procurou-se, por meio dos fundamentos da linguística e da antropologia, a retirada de traços do "comportamento verbal" da documentação na reconstituição de um fenômeno social que, neste caso, acusam subversivos e dignificam a "gente de bem". Nos discursos de condenação dos estudantes de esquerda ou de construção de um novo tipo de juventude, deixava-se em segundo plano os ritos, afetos, práticas. $\mathrm{O}$ que estava em jogo era a defesa de ideias mais urgentes, como a "ordem social", "o desenvolvimento", "subversão" etc. Os elementos circunstanciais, acidentais, ocultados, mesmo sendo consideraçóes menos importantes no momento do registro, foram itens observados durante a análise.

Os enunciadores apresentados pela documentação hierarquizaram o significado dos enunciados, estabelecendo maior ou menor importância aos eventos, acontecimentos e atos das pessoas implicadas. Os documentos foram lidos como produto de uma inter-relação especial, em que havia o desequilíbrio entre as partes envolvidas. Partindo do princípio de que uma série de comportamentos juvenis era registrada de modo a reforçar a subversão estudantil, busca-se nessa contraposição, compreender o que significava a ideia de estudante democrático, o que motivou essa qualificação e porque ela passou a ser enaltecida. 


\section{A posição conservadora da Revista da Editora do Brasil S/A}

A Revista EBSA era uma publicação mensal da Editora do Brasil. Foi lançada em 1947, quatro anos após a fundação da própria Editora, e desativada nos anos 1990. Tratava-se de um periódico educacional que foi intitulado "documentário de ensino". Em novembro de 1947, os editores pensaram a publicação como uma espécie de caderno de informaçóes educacionais para os profissionais de ensino de todos os segmentos, mas, especialmente, voltada para o Ensino Médio brasileiro e era tida como porta-voz dos editores. (EBSA, 1957, p. 1-4)

O periódico militava abertamente em nome da escola particular, posicionou-se como anticomunista e partidária à intervenção do exército no governo. Foi inteiramente favorável ao Golpe Militar de 1964, chamado de "Revolução". Nas páginas da Revista, era manifestada a indignação diante da "desordem pública", fato este que os editores simplesmente abominavam. Registrava-se como editora que contribuía para o engrandecimento do Estado e o bem-estar social da sua gente, "marchando paralela ao Governo". (EBSA, 1972, p. 1-8)

Em 1971, quando a imprensa sofria forte censura, os responsáveis pela EBSA orgulhavam-se de não ter tido seus escritos bloqueados. Isso é um indicativo de que suas ideias não entravam em choque com a ordem instituída ao ponto de passarem por uma censura. Mais do que isso, seus editores enalteciam o senso de organização dos militares e a rápida condução do país ao desenvolvimento. (EBSA, 1971, pp. 1-6) A Revista se proclamava "imparcial". Em outras palavras, os responsáveis assumiam a posição de quem se pretende influenciar os outros: a de neutralidade e fidelidade aos "fatos".

Os seus editores e os colaboradores publicados no periódico apresentavam imperativos de argumentação julgando que, à época, era muito arriscado pensar em mudanças sociais, acreditando que tais modificaçóes poderiam perverter as conquistas já definidas. As mobilizações políticas excessivas serviam apenas para evidenciar o baixo caráter daqueles que promoviam inquietaçóes na paz estacionária. O periódico era uma colagem de ideias conservadoras ao estilo da "tese de perversidade" e da "tese do risco", apresentadas por Hirschman (1997, p. 16). Isto é, divulgavam que todo movimento social que buscasse uma alteração brusca das características da sociedade, não podia ser levado a sério, porque, desta forma, corria-se o risco de perder todas as conquistas já programadas e feitas de forma paulatina. 


\section{Os "estudantes subversivos" e os "estudantes democráticos": duas representações juvenis nos anos 1960}

A primeira grande perturbação com os estudantes era o fato de eles se posicionarem contra o movimento em torno do "desenvolvimento do Brasil". Estudantes subversivos desaceleravam a marcha para o crescimento econômico no país. As consideraçôes publicadas também se voltaram aos aspectos educacionais, o que deu luz aos seus significados implícitos a partir da atuação dos sujeitos na escola. O que sustentava a ideia de subversão, em primeiro lugar, eram açóes tidas como inconvenientes e que desestabilizavam a rotina das pessoas.

Os ataques ao movimento estudantil tiveram três grandes focos. Primeiro, tinha-se em mente o tempo de preparação de um sujeito político. Isto é, um sujeito verdadeiramente político necessitava de um tempo de maturação, não nascia de forma espontânea em movimentos de rua. Depois, criticavam-se os estudantes que desrespeitavam as posiçóes de domínio dos mais velhos dentro das instituiçôes de ensino, fazendo púlpito político, piquetes, em horário de aulas. Por fim, atacavam-se os jovens militantes que não percebiam o quão precoce era a sua ação política, já que, um político verdadeiro fazia carreira na escola e, preferivelmente, tinha um diploma do ensino superior. ${ }^{2}$

A principal agressão para com os estudantes mobilizados ficou concentrada em uma suposta precocidade dos jovens em participar da política sem ter um devido preparo, feito à época, convencionalmente, por vias escolarizadas. A ideia de boa preparação política estava vinculada ao tempo de permanência do estudante nos bancos escolares e, mais ainda, ao tipo de ensino que ele recebia em sua trajetória, que deveria estar centrado, preferencialmente, no ensino secundário, depois, no ensino universitário. Fazer política era uma prática social de sujeitos adultos que tinham passado pelo processo de escolarização e não estava aberta a todos. No entanto, parte dos estudantes nos anos 1960 opinava sobre os critérios que demarcavam a posição dos sujeitos de autoridade e transformavam tribunas improvisadas em postos de comando político, o que aguçou a raiva dos discursos da imprensa. (BRAGHINI, 2010, pp. 108-109)

Segundo a proposta juvenil, era possível se destacar como sujeito político sem a necessidade de permanência nos bancos acadêmicos nem da ajuda dos mais velhos. Isso significa dizer que tais estudantes, brincavam com a ideia de que as "personalidades condutoras" seriam apenas aquelas que empunhavam uma titulação de nível superior. ${ }^{3}$ Portanto, a contrariedade dos jovens e a sua suposta precocidade política parecia apontar um distúrbio no sistema escolar do tipo clássico, que tinha exato objetivo de produzir a elite política brasileira. $\mathrm{O}$ potencial estudantil para agremiação feita a partir de incursões extraescolares era odiado, porque era visto como pouco aprofundados. 
Os estudantes renegavam a juventude como sendo um período de espera para a vida adulta. A vontade de ser guerrilheiro e lutar pela revolução socialista no Brasil apareciam como alternativas de trajetória de vida e, nos artigos, eram configuraçóes esdrúxulas ou atos desviantes de vida. (BRAGHINI, 2010, p. 259-260)

Em contrapartida, dentro do plano de saneamento dessa juventude rebelde foi apresentado outro grupo que se mostrava pouco à vontade com o governo de João Goulart [N.E.: João Belchior Marques Goulart, 240 Presidente do Brasil, período de 8 de setembro de 1961 a $1^{\circ}$ de abril de 1964]; ficava incomodado com as manifestaçóes estudantis de rua; eram compreendidos como uma boa juventude que se comprometia com o trabalho e com os estudos. Eles também atuavam politicamente, mas não seguiam os mesmos caminhos dos seus semelhantes "revoltados". Eles foram intitulados: "estudantes democráticos".

\section{Os "estudantes democráticos" eram a representação do bem: sensatos e pensadores da realidade}

O termo "estudantes democráticos" foi reforçado durante o processo de constituição da Lei Suplicy (Lei no 4.464). ${ }^{4}$ Foram chamados "democráticos" os estudantes que, em comitiva, foram até Brasília apontar sugestóes ao projeto de extinção da União Nacional dos Estudantes (UNE) e entidades congêneres. De acordo com a publicação, o próprio Ministro da Educação, Flávio Suplicy de Lacerda, teria recebido estudantes interessados em "analisar e apresentar ideias visando solucionar alguns casos no âmbito das entidades que os representam". (EBSA, 1964, p. 28-29)

Outros exemplos de estudantes democráticos foram surgindo em agremiações universitárias, manifestando-se contrários aos movimentos revolucionários de esquerda que se multiplicavam na América Latina. Esses grupos eram favoráveis às intervençóes militares estadunidenses em ambientes considerados perturbadores, fazendo coro com grande parte da imprensa brasileira que criticava as agitaçóes sociais, revolucionárias, vindas, por exemplo, da ilha de Cuba.

Uma parcela da juventude se sentia atraída por Cuba, também, porque se identificavam com os jovens líderes revolucionários, Che Guevara [N.E.: Ernesto Guevara de la Serna, ideólogo e comandante que liderou a Revolução Cubana] (1953-1959) (33 anos) e Fidel Castro [N.E.: Fidel Alejandro Castro Ruz, 15 Presidente de Cuba, período de 02 de dezembro de 1976 a 24 de fevereiro de 2008] (35 anos). Mas havia quem os odiasse. Enquanto a revolução se consolidava, um documento assinado pelo presidente do grêmio do Centro de Química Industrial 
do Colégio Oswaldo Cruz conclamava os seus colegas para que agissem contra os extremistas favoráveis a Fidel Castro, sujeito que era ateu, comunista e ditador.

O grêmio não aceitava que em nome de todos os estudantes houvessem manifestações favoráveis à Revolução em Cuba. Registrou: "Basta. Chega. Não mais permitiremos que uma minoria extremista fale em nome de nossa classe". O documento se apresentava como um "brado de alerta", a fim de impedir que o extremismo deteriorasse ainda mais "a mente de nossa juventude". (EBSA, 1964, p. 50-51)

Em 22 de outubro de 1961, foi noticiado pelo O Estado de S. Paulo (OESP) o IV Congresso Latino-Americano de Estudantes, realizado em Natal. A reportagem se concentrou no fato de que a maior parte do grupo de estudantes presentes era contrária à União Nacional dos Estudantes (UNE). Segundo o jornal, uma parcela dos estudantes presentes ao congresso julgou a entidade como traidora da causa estudantil "humanitária", pois se mostrava partidária à Federação de Estudantes Universitários (FEU), órgão que representava os estudantes cubanos no mesmo evento. Alguns estudantes se mostravam arredios com os fuzilamentos acontecidos na ilha. Para OESP, este ato teria sido uma "grande e merecida lição" aos estudantes da UNE, pois, o repúdio à propaganda política que se ergueu em prol do regime de Fidel Castro era uma prova de que havia estudantes "sensatos" em ação no Brasil. (EBSA, 1961, p. 35-36)

Da parte dos estudantes tidos por sensatos foi noticiada a produção de duas resoluçóes no congresso: uma, pedindo pelo fim dos fuzilamentos ordenados por Guevara, de modo a outorgar aos estudantes avessos ao regime instituído o máximo de garantias que o processo revolucionário permitisse; outra, pedindo à Comissão de Investigaçóes Estudantis (RIC) da Secretaria Coordenadora de Uniōes Nacionais de Estudantes (Cosec), para que fosse realizada uma investigação sobre a repressão que sofriam os estudantes cubanos oponentes do movimento revolucionário. (EBSA, 1961, p. 61-62)

No início dos anos 1960, alguns jovens se diziam nem a favor e nem contra aos movimentos estudantis sediados nas Universidades. Era o grupo dos neutros. No entanto, a existência de neutralidade já era reportada como ato democrático. A discordância entre jovens era motivo de análise e o conteúdo apelava sempre à desmobilização estudantil, na busca da estabilidade social. Os escritos se apegavam aos pontos de discórdia de forma a sobressaltar os maus atos juvenis e deixando claro que os jovens não se entendiam entre eles mesmos. Um exemplo desse gerenciamento publicitário da discordância entre os jovens aconteceu durante uma comunicação ocorrida entre os estudantes paulistas da Faculdade de Filosofia, Ciências e Letras da Universidade de São Paulo (FFCL-USP) e alunos pernambucanos, em relação à greve na Universidade de Pernambuco. 
No dia 06 de junho de 1961, a mando do Presidente da República, Jânio Quadros [N.E.: Jânio da Silva Quadros, 22․ Presidente do Brasil, período de 31 de janeiro de 1961 a 25 de agosto de 1961], foi encaminhado para universidade pernambucana, o Ministro da Educação, Brígido Tinoco [N.E.: Brígido Fernandes Tinoco, Ministro da Educação, período dezembro de 1930 a agosto de 1931 e dezembro de 1931 a setembro de 1932], acompanhado pelo Prefeito Miguel Arraes [N.E.: Miguel Arraes de Alencar, Prefeito de Recife, período de 1960 a 1962]. Ambos foram discutir o fim da greve de estudantes que lutavam por melhores condiçóes de ensino. (EBSA, 1961, p. 52-53) Dois dias depois, os alunos da FFCL-USP manifestaram a sua solidariedade aos colegas pernambucanos e protestaram sobre as "[...] eventuais arbitrariedades cometidas pela tropa do Exército [...]", a propósito da desocupação dos prédios. No entanto, os alunos da FFCL-USP sentiram "estranheza" para com a atitude de ocupação feita "indevidamente", junto aos "bens pertencentes ao Estado". (EBSA, 1961, p. 53)

Os alunos da USP expressaram confiança na "ação do Executivo para solucionar o problema"; apelaram para o "[...] bom senso dos colegas recifenses, no sentido de aguardarem as providências das autoridades [...]"; por fim, expressaram inquietação pelo fato de que "pessoas alheias à cultura e à tradição brasileiras" estavam "[...] contribuindo para conturbar a ordem necessária ao desenvolvimento harmônico dos verdadeiros interesses da Nação [...]”. (EBSA, 1964, p. 54-55) Por um lado, existe a estranheza em torno de açôes que ocupavam o espaço do prédio público; por outro, houve claro desacordo pela atuação daqueles que, à época, começaram a ser reconhecidos como estudantes profissionais.

Foi peculiar que os estudantes da FFCL-USP considerassem a ocupação da reitoria em Recife como uma ação bizarra. Ficar alojado dentro da instituição de ensino era uma prática nova de manifesto e, por isso, causava estranheza entre os próprios estudantes. Os jovens americanos, franceses, japoneses e alemães também utilizavam tal prática no mesmo período. Essa atuação demonstrou, além da circulação mundial de um costume inventado, a emersão de uma forma irreverente de uso dos espaços escolares, o que causou muito descontentamento. (HUERRE; REYMOND; REYMOND, 2000, p. 224)

Náo havia apoio irrestrito de seus pares, a respeito do uso de novas formas juvenis de combate e reivindicação. Ao contrário, a estranheza causou o pedido de cautela diante dos bens público e o apaziguamento das mobilizaçóes dentro da Universidade, ao ponto de se confiar nas autoridades competentes. A discordância entre as duas partes foi usada para apontar como os atos dos estudantes do Recife pareciam um frenesi inconsequente, diante da valorização ao patrimônio e do equilíbrio de pensamento dos estudantes paulistas. 
Não raro havia parcelas da juventude estudantil que se manifestavam entusiasmados com o golpe militar, em 1964. Os atos da União Metropolitana dos Estudantes (UME) são exemplos dessa militância em torno da intervenção militar armada. Apresentada como órgão máximo de representação dos universitários cariocas, enviou um comunicado à imprensa em abril de 1964, expressando sua confiança nas Forças Armadas, estando certos de que eles reconduziriam a Nação "à legalidade constitucional”.

Esse manifesto, assinado pelos estudantes Antônio Figueira Filho (Presidente), Evanildo Japiassú (Vice-Presidente), encarregado por assuntos ligados aos "Problemas Nacionais" e Lia Acquarene da Silva (2a secretária), se posicionava enfaticamente, contra os extremismos da esquerda e da direita. Os jovens tinham por interesse barrar "a ameaça comunista"; condenavam a apresentação dos estudantes como uma frente única, considerando-a uma "falsa política de unidade estudantil" e alertavam sobre a massificação de estudantes que se sentiam impedidos "a livre manifestação das vontades”, já que o outro grupo oprimia as consciências. Segundo o documento, havia preocupaçóes mais importantes e do interesse de todos, tais como a Reforma Universitária e a melhoria das condiçóes e técnicas de ensino, de modo que os jovens fossem preparados como "profissionais competentes para as tarefas do progresso nacional”. (EBSA, 1964, p. 58-59)

Com esse mesmo intuito do estudante Luciano Rodrigues Alves Pedroso, presidente do Diretório Estadual dos Estudantes do Estado de Sáo Paulo, partiu um manifesto de apoio ao General Castelo Branco [N.E.: Humberto de Alencar Castelo Branco, 26․ Presidente do Brasil, período 15 de abril de 1964 a 15 de março de 1967], pedindo uma ação diante da ameaça comunista "dentro da ordem, da lei e as instituiçôes de nosso país”. O manifesto repetia os bordóes sobre a ameaça comunista nos meios estudantis e era favorável ao uso de medidas voltadas à segurança nacional. Os colegas agitados deixariam a "verdadeira liderança nacional" estudar em paz. Por fim, o documento julgou que o uso da força existia contra as "minorias" insatisfeitas com o regime militar e essa ação valia a pena, diante do risco de se perder o "futuro da Pátria, o nosso futuro". (EBSA, 1965, p. 28-29)

Gustavo Corção, conhecido jornalista conservador, criticou no Diário de Notícias a peregrinação de estudantes por colégios e faculdades, buscando adesões em homenagem às Forças Armadas. $\mathrm{O}$ jornalista se mostrava apreensivo com a notícia da manifestação, pois, "[...] era feio o zelo desses moços que correm em homenagear os vencedores [...]" e que eles "deveriam abster-se desse tipo de atividade”.

A disposição do jornalista não era contrariar os "bons serviços prestados pelos militares”, mas, os estudantes não deveriam se mobilizar de forma alguma, sendo eles favoráveis ou contrários. Muito menos sair para longe das fronteiras 
da escola. O estudante "bom" optava pela escola. Adepto ou adverso, o estudante deveria permanecer nos bancos escolares, sob a ameaça de ser reconhecido como "filho de papai", pois assim eram chamados os jovens que tinham tempo para fazer passeata. O bom estudante, caso optasse por estar fora da escola, deveria se apresentar mais como discípulo e menos como tutor.

Parecia insuportável ver estudantes tomando às vezes de professores, que denotava a tentativa de ensinar aos mais velhos como deveria ser a condução política no país. (CORÇÃO, 1964, p. 66-67) ${ }^{5}$ Mesmo a Lei Suplicy, tão rechaçada pela bibliografia pertinente ao movimento estudantil, tinha os seus defensores entre os jovens. ${ }^{6} \mathrm{Um}$ mês antes à data prevista das eleiçóes gerais de representantes estudantis (16/09/1965), também foi noticiado que o Centro Acadêmico Oswaldo Cruz, da Faculdade de Medicina de Universidade de São Paulo (USP), realizou uma discussão entre professores e alunos com o propósito de examinar, "com espírito construtivo", a Lei no 4.464. Da parte do comentarista, esses estudantes e professores ganhavam mérito por terem compreendido o bom espírito do tal dispositivo. (EBSA, 1965, p. 33-34) ${ }^{7}$

Também não eram poucos os grupos estudantis que atuavam de maneira reservada, em espaços privados, clubes, escritórios e festas beneficentes, principalmente ao lado de senhoras que defendiam a família e o lar contra a ameaça comunista antes e depois do golpe militar. (SIMÓES, 1985, p. 82-83) O Congresso da Uniāo Paulista de Estudantes Secundários, em Santos; o Congresso da União Brasileira de Estudantes Secundários, em Pelotas e a I Convenção Cristã e Democrática dos Estudantes Secundários, em São Paulo, foram reunióes apontadas como patrocinadas pela Uniâo Cívica Feminina (UCF), no início dos anos 1960, na tentativa de dar apoio aos estudantes que buscavam desestabilizar o governo de João Goulart.

A Campanha da Mulher pela Democracia (Camde) fez a sua primeira manifestação pública durante a crise dos mísseis, em 1962, em conjunto com a "Vanguarda Universitária Católica", liga de estudantes universitários católicos. Tanto a UCF como a Camde foram lideranças responsáveis pela organização da "Marcha da Família com Deus pela Liberdade" e atuavam junto aos grupos estudantis, financiando-os em suas participaçóes em congressos, mesmo que promovidos pela UNE, ou os auxiliando nas oposiçóes feitas em diretórios acadêmicos.

$\mathrm{Na}$ "Marcha da Família com Deus pela Liberdade" os estudantes democráticos registrados foram: Grupo de Ação Patriótica (GAP), patrocinado pelo Instituto de Pesquisas e Estudos Sociais (Ipes); a Vanguarda Universitária Católica; Associação dos Estudantes Democratas; Movimento de Arregimentação dos Estudantes Democráticos (Maed); Frente Estudantil de São Paulo; Movimento Estudantil Democrático; Movimento Estudantil de São Paulo; Frente da Juven- 
tude Democrática; Associação de Estudantes Democratas; Associação Cristã de Moços (São Paulo e Rio de Janeiro); Frente da Juventude Democrática (Rio de Janeiro). (SIMÓES, 1985, p. 158-161)

A Polícia Federal, que investigou as entidades estudantis nacionais e internacionais, também apontou para dois grandes grupos estudantis anticomunistas atuantes no Brasil: a "Frente da Juventude Democrática" e a "Cruzada Estudantil Anticomunista". De acordo com o documento, os dois órgãos "não estavam filiados a nenhum outro órgão estudantil”, agiam isoladamente e estavam em desacordo com as diretrizes das demais entidades de estudantes que combatiam atos bolcheviques fora da do meio estudantil. A "Frente da Juventude Democrática" tinha um jornal denominado Democracia em Marcha e, segundo o relato, exercia influência nos congressos e demais atividades estudantis. ${ }^{8}$

Quando o periódico apresentava atos violentos vindos da parte de estudantes, optava em falar de "terroristas", assinalando-os como grupos que oprimiam o cidadão por meio de tocaias urbanas. Esse foi o caso do assassinato do diretor-geral da Fiat argentina, Oberdan Salustro, noticiado no OESP e transcrito no periódico educacional. De acordo com o jornal, esse ato de jovens extremistas buscava transformar a ação de "assassinatos comuns inconfundíveis" em movimento político. Segundo a reportagem, esse evento era tática de "gente sinistra". (EBSA, 1972, p. 37-38)

No entanto, a Revista se mantinha em silêncio, quando o caso tinha relação com atos violentos deflagrados por estudantes favoráveis ao governo militar e notórios por sua posição "anticomunista”. Podemos perceber essa ausência a partir de dois exemplos conhecidos e amplamente divulgados pela imprensa da época.

O primeiro deles foi noticiado pelo jornal Folha de S. Paulo (FSP), em 27 de outubro de 1967, e relatava o choque entre os estudantes da Universidade Mackenzie com os estudantes da Faculdade de Filosofia da Universidade de São Paulo (USP). A briga aconteceu para que fosse evitada a eleição da União Estadual dos Estudantes (UEE), DCE-Livre e do Grêmio da Faculdade de Filosofia que acontecia no prédio na Rua Maria Antônia, linha divisória entre as duas instituiçôes superiores. O jornal é irônico ao afirmar: "como quebrar a rotina das aulas". (FSP, 1967, p. 6) O segundo caso, foi apresentado em 19 de julho de 1968, quando o mesmo jornal divulgava a invasão de um grupo de estudantes no Teatro Galpão que atacou os atores da peça Roda Viva de Chico Buarque. Vinte sujeitos entraram no teatro após a peça armados de cassetetes e soco-inglês, espancaram, sobretudo as atrizes, e quebraram os assentos, equipamentos elétricos e camarins. (FSP, 1968, caderno 1, fl. A) Esses dois eventos orquestrados pelo, depois reconhecido, Comando de Caça aos Comunistas (CCC).

O grupo conhecido por CCC era eminentemente formado por estudantes da Universidade Mackenzie. Havia, também, em menor número, alunos da 
Faculdade de Direito do Largo de São Francisco (USP). À época, Pedro Medeiros, jornalista da revista $O$ Cruzeiro os chamou de "neonazistas". O artigo fez entrevistas com os seus membros e, quando citados, parte deles se pronunciou como sujeitos "armados" e lutadores de artes-marciais. (MEDEIROS, 1968, p. 19-23)9

O grupo atuava em conjunto com dois outros braços políticos, a Frente Anticomunista (FAC) e Movimento Anticomunista (MAC). Juntos ficaram conhecidos como a "pirâmide do terror" e estão diretamente relacionados com essa omissão do periódico educacional, que preferia destacar a ideia de um movimento estudantil atuante, mas que se portava de formava branda diante do fechamento do regime.

Este grupo não era um exemplo a ser apresentado em uma revista educacional. Mas, pelo apagamento, também não eram diretamente associados àqueles que, à época, eram tidos por "terroristas" que, no caso, era o termo que definia os membros de facçóes ligadas aos movimentos de esquerda, no final da década de 1960 e início dos anos $1970 .^{10}$

\section{Considerações finais}

A existência de jovens se manifestando, por si só, já é uma força capaz de acionar os movimentos conservadores. $\mathrm{O}$ artigo detectou a reação de um grupo diante do ativismo dos jovens estudantes avessos à ditadura militar. Ao invalidar as ações de uma parcela da juventude contestadora, esse grupo fez surgir uma juventude exemplar, apresentada como alternativa histórica daqueles que não se ajustavam a uma realidade. Julgou-se que a participação de estudantes em associaçóes estudantis era válida, quando praticada por meio de uma política de conciliação, principalmente associada às ideias oficiais ou se tutelada por um adulto.

A ideia de que o movimento estudantil naqueles anos esteve sempre ativo, rebelde e contrário ao fechamento das liberdades civis também é um senso comum. Existiam jovens dispostos a atitudes pouco progressistas ou totalmente reacionárias. O conservadorismo não é uma característica adstrita aos mais velhos.

Nem todos os estudantes pareciam dispostos a defender os atos revolucionários de vertente socialista. Não faziam coalizóes com os estudantes que tinham em Fidel e Che Guevara, exemplos de líderes históricos. Mesmo que houvesse consenso em benefício de causas consideradas maiores, como a melhoria do ensino público, havia discordância quanto às formas de reivindicação. Uma tendência juvenil desqualificava as manifestaçóes de rua; desdenhava da juventude rebelde; concentrava as suas perspectivas para as açóes que estivessem ligadas à 
rotina estudantil mais imediata e, por fim, como sonho futuro, vislumbravam muito mais o desenvolvimento nacional como resultado do trabalho.

Havia manifestações políticas estudantis que não tinham relação com as grandes passeatas de rua. Eram feitas em espaços privados, escolas, universidades, salóes, escritórios e reuniōes fechadas. Os estudantes democráticos tinham táticas que expressavam suas relaçóes sociais: de tutela; vinculado aos movimentos anticomunistas organizados por adultos. As manifestaçóes juvenis eram variadas, esses grupos não eram poucos e atuavam ou depreciando pessoas da mesma idade, ou como representantes passivos da boa sociedade. Aumentaram o coro do descontentamento pela instabilidade política que parecia transparecer das passeatas, gerando o medo que justificava a guarda militar da sociedade.

Jovens que pediam por sossego também entravam nos critérios válidos aos estudantes democráticos. Na carta intitulada "Estudantes Silenciosos", publicada originalmente no Jornal do Brasil, em maio de 1977, o estudante de Direito Edgard Marinho Bessa bem caracteriza o que era o "silêncio" em período de ditadura.

O autor julgava que "maioria silenciosa" era o grupo que não participava de atos públicos, nem de passeatas. Para ele a opinião política era formada pelo estudo. Pedia pela aplicação da lei em nome da paz e a ordem do país. Pediu para que a "minoria ruidosa" defendesse as suas ideias nos bancos escolares, procurando "saber mais". E cabia à juventude estudantil fazer os prognósticos corretos para, no momento certo, assumir a direção do país. (EBSA, 1977, p. 3)

Em 1977, esse estudante repetiu exatamente os mesmos argumentos que foram caros a uma variedade de grupos na década anterior. Como membro de uma nova geração universitária, carregou essa posição de quietude como uma herança vinda dos mais velhos, como legado escolar. $\mathrm{O}$ estudante se pronunciou em defesa do silêncio. Percebe-se no tempo a reiteração desse comportamento reticente ao longo dos anos que se seguiram. Momento em que o silêncio era divulgado como ação de gente valorosa.

\section{Notas}

1. Foram contabilizados 82 artigos vindos da imprensa diária, dentro de um lote de 211 artigos. Os jornais mais utilizados para a transcrição de artigos foram: O Estado de S. Paulo (18), Diário de Notícias (10), Jornal do Brasil (10), O Globo (8), Jornal do Comércio (7), Diário de S. Paulo (5), O Jornal (5), entre outros.

2. Mercenários; gatuno, patife; politiqueiros, demagogos; sem escrúpulos; torpes; desonestos, "assafadados"; maliciosos, mascarados, corruptos, mercenários; sub-reptícios, "lobos em pele de cordeiros"; tristes, feios também foram outros adjetivos usados para apontar o mesmo tipo de estudantes em diversos jornais brasileiros do período. (BRAGHINI, 2010, p. 111 e 120) 
3. Tratava-se da ideia de formação de uma elite condutora que levasse a massa governada por "imitação". As "individualidades condutoras" eram a apresentaçáo de homens maiores que, formados pela escolarização serial, processual, de elite e patriótica davam poder a esses sujeitos para assumirem as maiores responsabilidades na condução do país. (Decreto-Lei n. 4.244 - de 9 de abril de 1942)

4. O termo "estudantes democráticos" já tinha sido usado pela imprensa paulista em outras ocasiōes. Para designar os estudantes que se manifestavam a favor da candidatura de João Pessoa à Presidência da República. (OESP, 07/09/1929, p. 7) Depois, para os jovens que marcharam contra o mercado negro e a carestia fazendo coro com a União Democrática Nacional (UDN). (OESP, 18/09/1946, p. 3) O termo também foi utilizado em contraposição aos estudantes "comunistas" na União Nacional dos Estudantes (UNE). (OESP, 10/08/1954, p. 15) Isso quer dizer que essa expressão circulava pela imprensa há tempos, sendo usada de acordo com as conveniências políticas. Desde a década de 1950, foi usado como sujeitos contrários às mobilizaçóes comunistas”.

5. Transcrito do Diário de Notícias, Rio de Janeiro, 28/04/1964.

6. A Lei $\mathrm{n}^{\circ}$ 4.464, de 9 de novembro de 1964, ficou conhecida como Lei Suplicy de Lacerda. Instituiu como forma legal o funcionamento do Diretório Acadêmico (DA), restrito aos cursos, e o Diretório Central dos Estudantes (DCE), como entidade central dos estudantes dentro das universidades. A ideia era a de enfraquecer a ação da União Nacional dos Estudantes (UNE), jogando-a na ilegalidade. A ação bloqueava a atuação estudantil nacional e buscava cercar a ação da UNE dentro das instituiçóes de ensino.

7. Transcrito de OESP, São Paulo, 18/07/1965.

8. Centro de Referência da Luta Política "Memórias Reveladas": BRAN, Rio X9. O.ESI, ACL, 1/9.

9. Segundo a reportagem, no caso da invasão à USP, representando o CCC estavam presentes: Francisco José Aguirre Menin (comandou ataque à USP), Lionel Zaclis, Bernardo MacDowell Krug (armado) Boris Casoy ou Kassoy, José Roberto Batoquio. No caso da invasão feita à peça Roda Viva estavam presentes: João Marcos Flaquer, Estevão Augusto dos Santos Pereira, Paulo Roberto Chaves de Lara, Luis Correa Salles, Araken Testa, Silvio Salvo Venosa, Augusto Florestan, Claudio Leite, Dilermando Agágua, Mario Verangieri, Nelson Manganelo, Luis Antônio Sacari, Mário Boito, Antônio Succar Filho, José Auguso Bauer, Newton Camargo Rosa. Os seguintes alunos: Cássio Scatena (conhecido como Blanco), Cícero A. J. Gubeissi (armado), Jean Koudalla, Roberto Ulhoa Cintra eram alunos da Faculdade de Direito do Largo de São Francisco da USP e também participaram do ataque ao Teatro Galpão. Estudantes que estiveram nos dois eventos: Souvenir Assumpção Sobrinho (armado), Raul Nogueira Lima (conhecido como Raul Careca, armado), Estefan Buriti Suzian, Flavio Caviglia, e Marcio Penchas. Outros nomes vinculados ao CCC e citados na reportagem de O Cruzeiro (09/11/1968): Milton Moraes Zélio, Francisco Antônio Fraga, Paulo F. Campos, Salles de Toledo, Dilermando Cicagna Júnior, Fernando Forte, Percy Ed Hackemann, Paulo R. Ferreira Eugênio (armado), Fernando Piza, José Lamartine Sátiro (armado), Acácio Vaz de Lima Sobrinho, Paulo Flaquer, Pedro José Liberal (armado), João Parisi Filho (armado), José Antônio de Oliveira Machado (armado), Henrique Meira Castro (armado), Raffi Katlian, Chacon (informante), Douglas (sem sobrenome).

10. Como por exemplo: Movimento Nacional Revolucionário (MNR); Ação Libertadora Nacional (ALN); Movimento Revolucionário 8 de Outubro (MR-8); Vanguarda Popular Revolucionária (VPR); Ação Popular (AP); Política Operária (Polop); Vanguarda Armada Revolucionária Palmares (VAR-Palmares); Movimento de Libertação Popular (Molipo); Comando de Libertação Nacional (Colina); Forças Armadas de Libertação Nacional (FALN). 


\section{Fontes}

A UDN ao lado dos estudantes contra o "mercado negro". O Estado de S. Paulo. Sáo Paulo, 18 de setembro de 1946 .

ARQUIVO NACIONAL. Centro de Referência da Luta Política "Memórias Reveladas": BRAN, Rio X9. O.ESI, ACL, 1/9.

BESSA, E. M. Estudantes Silenciosos. Revista da Editora do Brasil S/A, São Paulo, n. 350, p. 33, maio, 1977.

BRASIL. Decreto-Lei n. 4.244, de 9 de abril de 1942. Lei Orgânica do Ensino Secundário Brasília, DF., Diário Oficial da Uniáo, 10 de abril de 1942.

. Lei 4.024, de 20 de dezembro de 1961. Fixa as Diretrizes e Bases da Educação Nacional. Brasília, DF., Diário Oficial da União, 27 de dezembro de 1961.

CORÇÃO, G. As manifestações estudantis. Revista da Editora do Brasil S/A. São Paulo, n. 193, p. 66-67, abril, 1964.

DE REPENTE, violência. USP faz fechar faculdades. Folha de S. Paulo. São Paulo, 27 de outubro de 1967.

EBSA. No limiar da segunda década. Revista da Editora do Brasil S/A. São Paulo, n. 121, novembro, p. 1-4, 1957.

. O problema estudantil. Revista da Editora do Brasil S/A. São Paulo, n. 208, setembro, p. 33-34, 1965.

. Ano de renovação. Revista da Editora do Brasil S/A. São Paulo, n. 285, dezembro, p. 1-6, 1971.

. Denúncia dos estudantes - Faculdade de Direito. Revista da Editora do Brasil S/A. Sáo Paulo, n. 159, maio, p. 54-55, 1964.

. Estudantes contra os extremismos e o falso nacionalismo - UME - Guanabara.

Revista da Editora do Brasil S/A. São Paulo, n. 193, abril, p. 28-29, 1964.

. Estudantes reagem contra a agitação dos extremistas. Revista da Editora do Brasil S/A. São Paulo, n. 157, março, p. 50-51, 1964.

. IV Congresso Latino Americano de Estudantes. Revista da Editora do Brasil S/A. São Paulo, n. 163, outubro, p. 32-36, 1961.

. O ensino médio em 1960. Revista da Editora do Brasil S/A. São Paulo, n. 162, abril, p. 24-25, 1961.

. O Presidente e os estudantes - Diretório Estadual dos Estudantes do Estado de São Paulo. Revista da Editora do Brasil S/A. São Paulo, n. 211, agosto, p. 28-29, 1965.

. Representação Estudantil. Revista da Editora do Brasil S/A. São Paulo, n. 201, dezembro, p. 58-59, 1964. 
EDITORA DO BRASIL S/A. Os “jovens idealistas sem máscara”. Revista da Editora do Brasil S/A. São Paulo, n. 288, março, p. 37-38, 1972.

$\overline{1972 .}$

. Paz na Terra. Revista da Editora do Brasil S/A. São Paulo, n. 297, dezembro, p. 1-8,

ESTUDANTES democráticos vencem as eleições na UNE. O Estado de S. Paulo. São Paulo, 10 de agosto de 1954.

INVADIDO e depredado o Teatro Galpão. Folha de S. Paulo. São Paulo, 19 de julho de 1968.

O PARTIDO democrático e a sucessão. O Estado de S. Paulo. São Paulo, 07 de setembro de 1929.

PALÁCIO DO PLANALTO. Nota oficial. Revista da Editora do Brasil S/A. São Paulo, n. 159, junho, p. 52-53, 1961.

\section{Referências}

BESSA, E. M. Estudantes Silenciosos. Revista da Editora do Brasil S/A, São Paulo, n. 350, p. 33, maio, 1977.

BRAGHINI, K. M. Z. A “Vanguarda Brasileira”: A juventude no discurso da Revista da Editora do Brasil S/A (1961-1980). 2010. 350p. Tese (Doutorado em Educação) PEPG em Educação: História, Política, Sociedade (EHPS), PUC-SP, São Paulo. 2010.

GINZURG, C. O inquisidor como antropólogo: Uma analogia e suas implicaçôes. In: . A micro-história e outros ensaios. Lisboa: Difel, 1989.

HILSDORF, M. L. S.; PERES, F. A. Estudos históricos sobre juventude: estado da arte. In: SPÓSITO, M. P. (Org.). Estado da Arte sobre juventude na pós-graduação brasileira: educação, ciências sociais e serviço social (1999-2006). Belo Horizonte: Argvmentvm, v. 2, 2009 p. 213-231.

HIRSCHMAN, A. O. O Pensamento Conservador: perversidade, futilidade e risco. Algés: Difel - Difusão Editorial, 1997.

HUERRE, P., REYMOND, M. P., REYMOND, J. M. Adolescência não existe: Histórias das atribulaçôes de um artifício. Lisboa: Terramar - Editores, Distribuidores e Livreiros Ltda., 2000.

MARTINS, J. S. O senso comum e a vida cotidiana. In: . A sociabilidade do homem simples: cotidiano e história na modernidade anômala. São Paulo: Contexto, 1998.

MEDEIROS, P. CCC e o comando do terror. O Cruzeiro. São Paulo: Diários Associados, p. 19-23, nov., 1968.

SANFELICE, J. L. A UNE e a Ditadura Civil-Militar de 1964. In: GROPPO, L. A.; ZAIDAN-FILHO, M.; MACHADO, O. L. (Orgs.). Juventude e Movimento estudantil: ontem e hoje. Recife: Editora Universitária da UFPE, 2008. 
"Estudantes democráticos"

SARLO. B. Tempo Passado: cultura da memória e guinada subjetiva. São Paulo: Companhia das Letras, 2007.

SIMÓES, S. D. Deus, Pátria e Família: as mulheres no Golpe de 1964. Petrópolis: Vozes, 1985.

Recebido em 30 de janeiro de 2015.

Aprovado em 23 de outubro de 2015.

DOI: http://dx.doi.org/10.1590/ES0101-73302015145476 